\title{
Von Willebrand factor, thrombomodulin, thromboxane, $\beta$-thromboglobulin and markers of fibrinolysis in primary Raynaud's phenomenon and systemic sclerosis
}

\author{
A L Herrick, K Illingworth, A Blann, C R M Hay, S Hollis, M I V Jayson
}

\begin{abstract}
Objective-To determine whether measurement of different markers of endothelial damage, activation of coagulation, and platelet activation might differentiate between patients with primary Raynaud's phenomenon (PRP), limited cutaneous and diffuse systemic sclerosis (lcSSc and dSSc), and healthy control subjects.

Methods-Under carefully controlled conditions, fasting blood was drawn from 19 healthy control subjects, 10 patients with PRP, 17 with IcSSc and nine with dSSc for measurement of the following: von Willebrand factor (VWF) and soluble thrombomodulin as markers of endothelial damage/activation, thromboxane (as thromboxane $B_{2}$ ) and $\beta$-thromboglobulin as markers of platelet activation, and tissue plasminogen activator antigen, tissue plasminogen activator activity and plasminogen activator inhibitor-1 (PAI-1) as markers of fibrinolysis.
\end{abstract}

Results-VWF was increased significantly in patients with SSc, and there was also a linear trend for thromboxane and tissue plasminogen activator antigen (in addition to VWF) to differentiate between different subgroups of patients with Raynaud's phenomenon. Patients with dSSc had the highest values. A combined index of VWF and thromboxane showed a highly significant trend across the four groups studied.

Conclusion-VWF, and to a lesser extent thromboxane and tissue plasminogen activator antigen, are associated with disease severity in patients with Raynaud's phenomenon. Prospective studies are now required to establish if these parameters can be used as markers of disease progression.

(Ann Rheum Dis 1996; 55: 122-127)

In systemic sclerosis (SSc), endothelial damage and platelet activation may occur and both these processes may contribute to the peripheral ischaemia so characteristic of this disease. The pathogenesis of SSc is, however, unclear. One school of thought is that the 'primary fault' in SSc is in the vasculature. ${ }^{12}$

Objective assessment of the severity of vascular disease in patients with either primary Raynaud's phenomenon (PRP) or Raynaud's phenomenon secondary to SSc is notoriously difficult. In recent years and in many medical specialties there has been great interest in the endothelium, and 'markers' of endothelial injury are now better defined. In this study markers of endothelial injury, of platelet activation, and of fibrinolysis were measured in patients with primary Raynaud's phenomenon, limited cutaneous SSc (lcSSc) and diffuse SSc (dSSc), and compared with those in healthy control subjects. Our hypothesis was that if concentrations of these markers, singly or in combination, were greater in patients with more severe Raynaud's - that is, occurring secondary to SSc-they might in future be useful in gauging the severity of vascular damage in patients with Raynaud's phenomenon.

We chose to measure von Willebrand factor antigen (VWF), soluble thrombomodulin, thromboxane, $\beta$-thromboglobulin, tissue plasminogen activator antigen, tissue plasminogen activator activity, and plasminogen activator inhibitor-1 (PAI-1). Increased concentrations of VWF in the circulation may reflect endothelial injury and VWF has previously been shown to be increased in patients with PRP and SSc. ${ }^{3-12}$ Soluble thrombomodulin, another marker of endothelial damage, has been studied less than VWF in SSc. The formation of thromboxane, a potent vasoconstrictor and platelet aggregator, has also been found to be increased in patients with SSc. ${ }^{13}$ Increased concentrations of thromboxane and $\beta$ thromboglobulin, released from platelet alpha granules, both reflect platelet activation, and increases in $\beta$-thromboglobulin have also been reported in patients with SSc. ${ }^{413-18}$ Fibrinolysis is primarily a function of the endothelium and we measured tissue plasminogen activator antigen, tissue plasminogen activator activity, and PAI-1 as markers of this process. Fibrinolysis has been shown to be impaired in patients with Raynaud's phenomenon secondary to SSc and other connective tissue disorders. ${ }^{19} 20$ We were particularly interested in tissue plasminogen activator antigen, as this is a product of the endothelium and may increase in concentration when the endothelium is damaged or activated. ${ }^{1021}$

Patients and methods

We studied 10 patients with PRP, 17 patients with lcSSc, nine patients with dSSc, and 19 
Table 1 Clinical characteristics of patients and controls

\begin{tabular}{cllll}
\hline & $\begin{array}{l}\text { Sex } \\
(M / F)\end{array}$ & $\begin{array}{l}\text { Age } \\
(y r)\end{array}$ & $\begin{array}{l}\text { Duration of } \\
\text { Raynaud's } \\
(y r)\end{array}$ & $\begin{array}{l}\text { Smokers } \\
(\%) \dagger\end{array}$ \\
\hline $\begin{array}{c}\text { Controls } \\
(\mathrm{n}=19)\end{array}$ & $6 / 13$ & $\begin{array}{l}40 \cdot 7 \\
(8 \cdot 4)\end{array}$ & - & $8(42)$ \\
$\begin{array}{c}\text { PRP } \\
(\mathrm{n}=10)\end{array}$ & $3 / 7$ & $\begin{array}{l}43 \cdot 1 \\
(9 \cdot 3)\end{array}$ & $\begin{array}{l}9 \cdot 1 \\
(8 \cdot 6)\end{array}$ & $4(40)$ \\
$\begin{array}{c}\text { lcSSc } \\
(\mathrm{n}=17)\end{array}$ & $2 / 15$ & $\begin{array}{l}51 \cdot 2^{\star} \\
(10 \cdot 3)\end{array}$ & $\begin{array}{l}16 \cdot 4 \\
(9 \cdot 7)\end{array}$ & $8(47)$ \\
$\begin{array}{c}\text { dSSc } \\
(\mathrm{n}=9)\end{array}$ & $3 / 6$ & $\begin{array}{l}51 \cdot 35 \\
(8 \cdot 5)\end{array}$ & $\begin{array}{l}12 \cdot 7 \\
(12 \cdot 0)\end{array}$ & $1(11)$ \\
\hline
\end{tabular}

Values are mean (SD) or tnumber (\%).

PRP = Primary Raynaud's phenomenon; lcSSc, dSSc = limited cutaneous, and diffuse, systemic sclerosis.

${ }^{\star} \mathrm{p}=0.002, \mathrm{\S} \mathrm{p}=0.007$, compared with controls

healthy control subjects who did not suffer from Raynaud's phenomenon; table 1 shows their clinical data. None of the patients with PRP had underlying connective tissue disease and all had had Raynaud's phenomenon for at least two years. All but two patients with SSc fulfilled the American Rheumatism Association criteria for $\mathrm{SSc}^{22}$ both these patients had severe Raynaud's phenomenon and abnormal nail fold microscopy and were diagnosed as having lcSSc on the basis of calcinosis, telangiectasia and anticentromere antibody in the first patient, and digital pitting and reduced peristalsis on barium swallow in the second. In those patients classified as having lcSSc, skin thickening was confined to the face and extremities, whereas those with dSSc had more widespread skin involvement. Patients were asked specifically if they were taking aspirin or any other non-steroidal antiinflammatory drug; if so, they were excluded from the study. Vasodilator treatment was being taken by three patients with PRP (one thymoxamine, one topical glyceryl trinitrate, one nicotinic acid), 11 of the lcSSc subgroup (eight nifedipine, one verapamil, one ketanserin, one topical glyceryl trinitrate), and four of the dSSc subgroup (one captopril and nifedipine, one captopril, one nifedipine, one diltiazem). With respect to medications that may have had an effect on the underlying disease process, two patients with lcSSc and three with dSSc were receiving prednisolone, two with dSSc were taking penicillamine (one of them was also taking prednisolone), one dSSc patient was taking cyclophosphamide (in addition to prednisolone) and one dSSc patient was receiving interferon alpha.

Blood was obtained between 09:00 and 10:00 from fasted, resting subjects for measurement of the different markers of vascular injury, platelet activation, and fibrinolysis. Care was taken to avoid platelet activation, by the use of atraumatic needle puncture, a butterfly needle, and minimal stasis with tourniquet release before blood withdrawal into $10 \mathrm{ml}$ syringes. Smokers were asked to abstain from cigarettes from the previous midnight.

Plasma was prepared for measurement of VWF, soluble thrombomodulin, tissue plasminogen activator antigen, and PAI-1 by collection of blood into $3 \cdot 13 \%$ trisodium citrate (nine parts blood, one part anticoagulant) and centrifugation within 20 minutes of venepuncture, at $3000 \mathrm{~g}$ and $4^{\circ} \mathrm{C}$, for 30 minutes. For measurement of tissue plasminogen activator activity, plasma was prepared by acidification of $1 \mathrm{ml}$ of citrated blood with $0.5 \mathrm{ml}$ of acetate buffer and separated as above before further acidification of $800 \mu \mathrm{l}$ with $80 \mu \mathrm{l}$ of $20 \%$ acetic acid.

Thromboxane was measured as thromboxane $B_{2}$ by collection of $5 \mathrm{ml}$ of blood into $170 \mu \mathrm{l}$ of $100 \mathrm{mg} / \mathrm{ml}$ EDTA/saline, $33 \mu \mathrm{l}$ of $120 \mathrm{mg} / \mathrm{ml}$ aspirin/ethanol and $100 \mu \mathrm{l}$ of $0.9 \%$ saline before centrifugation as above.

Plasma was prepared for measurement of $\beta$-thromboglobulin by collection of $4.5 \mathrm{ml}$ of blood into diatube $\mathrm{H}$ tubes (Diagnostica Stago, Asnieres-sur-Seine, France) containing the manufacturer's mixture of sodium citrate, citric acid, and the platelet inhibitors theophylline, adenosine, and dipyridamole. The blood was kept on ice for between 30 and 60 minutes before centrifugation at $4^{\circ} \mathrm{C}$, at $2500 \mathrm{~g}$ for 30 minutes. During collection of plasma, care was taken not to disturb the platelet layers.

All samples were stored at $-80^{\circ} \mathrm{C}$ until required for assay.

VWF was measured by standard enzyme linked immunosorbent assay (ELISA) techniques using commercially available antisera. ${ }^{1123}$ Plasma soluble thrombomodulin was measured according to the manufacturer's instructions using a standard one stage immunoassay with two monoclonal antibodies (Fuji, Japan). Thromboxane $\mathrm{B}_{2}$ was measured according to the manufacturer's instructions using a standard thromboxane $\mathrm{B}_{2}$ ELISA kit (Cayman Chemicals Company, Michigan). $\beta$-Thromboglobulin was measured using a standard Asserachrom $\beta$-thromboglobulin ELISA kit (Diagnostica Stago).

Tissue plasminogen activator antigen, tissue plasminogen activator activity, and PAI-1 were measured using Biopool Immulyse ${ }^{\mathrm{TM}}$ tissue plasminogen activator, Biopool Spectrolyse ${ }^{\mathrm{TM}} /$ fibrin and Biopool Spectrolyse (PL) PAI kits, respectively (Biopool, Umea, Stago).

\section{STATISTICAL ANALYSIS}

Unpaired $t$ tests were used for between group comparisons. Analysis of variance was used to adjust for the effect of age and smoking and correction for multiple comparisons. Soluble thrombomodulin, thromboxane, $\beta$-thromboglobulin, tissue plasminogen activator antigen, and PAI-1 were log transformed to achieve normality. Before log transformation, a value of $1 \mathrm{U} / \mathrm{ml}$ was added to the PAI- 1 results to allow for results of $0 \mathrm{U} / \mathrm{ml}$. Pearson's product moment correlation coefficient was used to measure associations between the different parameters. Discriminant analysis (using SPSS) was used to investigate the relationship between VWF and thromboxane in healthy controls and the different patient subgroups. With the number of subjects in each group detailed above, it is possible to detect a difference of between 1.2 and 1.9 standard deviations between the groups with $80 \%$ power at the $1 \%$ significance level. 
Table 2 Von Willebrand factor (VWF), soluble thrombomodulin (sTm), thromboxane, $\beta$-thromboglobulin ( $\beta$-TG), and markers of fibrinolysis in patients and control subjects

\begin{tabular}{|c|c|c|c|c|c|c|c|}
\hline & $\begin{array}{l}V W F \\
(I U / d l)\end{array}$ & $\begin{array}{l}s T m \\
(n g / m l)\end{array}$ & $\begin{array}{l}\text { Thromboxane } \\
(\mathrm{pg} / \mathrm{ml})\end{array}$ & $\begin{array}{l}\beta-T G \\
(I U / m l)\end{array}$ & $\begin{array}{l}\text { t-PA antigen } \\
(\mathrm{ng} / \mathrm{ml})\end{array}$ & $\begin{array}{l}t-P A \text { activity } \\
(I U / m l)\end{array}$ & $\begin{array}{l}P A I-1 \\
(U / m l)\end{array}$ \\
\hline $\begin{array}{l}\text { Controls } \\
\quad(n=19) \dagger\end{array}$ & $\begin{array}{l}96 \\
(30) \\
(n=19) \ddagger\end{array}$ & $\begin{array}{l}1 \cdot 0 \\
(0 \cdot 8 \text { to } 1 \cdot 3) \\
(\mathrm{n}=19)\end{array}$ & $\begin{array}{l}37 \\
(27 \text { to } 50) \\
(\mathrm{n}=18)\end{array}$ & $\begin{array}{l}47 \\
(36 \text { to } 62) \\
(n=18)\end{array}$ & $\begin{array}{l}6 \cdot 2 \\
(5 \cdot 1 \text { to } 7 \cdot 7) \\
(\mathrm{n}=19)\end{array}$ & $\begin{array}{l}0 \cdot 72 \\
(0 \cdot 25) \\
(n=18)\end{array}$ & $\begin{array}{l}4 \cdot 5 \\
(2 \cdot 6 \text { to } 7 \cdot 2) \\
(\mathrm{n}=19)\end{array}$ \\
\hline $\begin{array}{l}P R P \\
\quad(n=10)\end{array}$ & $\begin{array}{l}103 \\
(23) \\
(\mathrm{n}=10)\end{array}$ & $\begin{array}{l}1 \cdot 2 \\
(0 \cdot 8 \text { to } 1 \cdot 8) \\
(\mathrm{n}=10)\end{array}$ & $\begin{array}{l}40 \\
(20 \text { to } 80) \\
(n=10)\end{array}$ & $\begin{array}{l}47 \\
(30 \text { to } 75) \\
(n=10)\end{array}$ & $\begin{array}{l}6 \cdot 5 \\
(4 \cdot 5 \text { to } 9 \cdot 3) \\
(n=10)\end{array}$ & $\begin{array}{l}0.63 \\
(0 \cdot 28) \\
(n=9)\end{array}$ & $\begin{array}{l}7 \cdot 5 \\
(4 \cdot 3 \text { to } 12 \cdot 6) \\
(n=10)\end{array}$ \\
\hline $\begin{array}{l}\operatorname{lcSSc} \\
\quad(\mathrm{n}=17)\end{array}$ & $\begin{array}{l}1290 \\
(35) \\
(n=16)\end{array}$ & $\begin{array}{l}1 \cdot 4 \\
(0 \cdot 8 \text { to } 2 \cdot 4) \\
(\mathrm{n}=16)\end{array}$ & $\begin{array}{l}60 \\
(37 \text { to } 97) \\
(n=16)\end{array}$ & $\begin{array}{l}72^{\star} \\
(51 \text { to } 102) \\
(\mathrm{n}=16)\end{array}$ & $\begin{array}{l}7 \cdot 6 \\
(5 \cdot 9 \text { to } 9 \cdot 8) \\
(n=15)\end{array}$ & $\begin{array}{l}0.89 \\
(0.32) \\
(n=14)\end{array}$ & $\begin{array}{l}1 \cdot 8 \# \\
(0 \cdot 5 \text { to } 4 \cdot 0) \\
(n=15)\end{array}$ \\
\hline $\begin{array}{l}\mathrm{dSSc} \\
\quad(\mathrm{n}=9)\end{array}$ & $\begin{array}{l}1549 \\
(50) \\
(n=9)\end{array}$ & $\begin{array}{l}1 \cdot 3 \\
(0 \cdot 7 \text { to } 2 \cdot 5) \\
(\mathrm{n}=9)\end{array}$ & $\begin{array}{l}101 \\
(34 \text { to } 303) \\
(n=9)\end{array}$ & $\begin{array}{l}63 \\
(42 \text { to } 94) \\
(n=9)\end{array}$ & $\begin{array}{l}10 \cdot 1 \\
(5 \cdot 1 \text { to } 19 \cdot 9) \\
(\mathrm{n}=8)\end{array}$ & $\begin{array}{l}0.73 \\
(0.31) \\
(\mathrm{n}=7)\end{array}$ & $\begin{array}{l}5 \cdot 1 \\
(1 \cdot 1 \text { to } 17 \cdot 2) \\
(\mathrm{n}=8)\end{array}$ \\
\hline
\end{tabular}

Values are geometric mean ( $95 \%$ confidence interval) or mean (SD).

$\dagger$ Numbers in groups; $\ddagger$ numbers of individuals tested within groups.

$\mathrm{t}-\mathrm{PA}=$ Tissue plasminogen activator; PAI-1 = plasminogen activator inhibitor-1; PRP = primary Raynaud's phenomenon; lcSSc $\mathrm{dSSc}=$ limited cutaneous, and diffuse, systemic sclerosis.

${ }^{\star} \mathrm{p}=0.05$ compared with controls; $\mathrm{S} \mathrm{p}=0.005 v$ controls and $\mathrm{p}=0.03 v \mathrm{PRP} ; \boldsymbol{\mathrm { p }}=0.009 v$ controls and $\mathrm{p}=0.02 v \mathrm{PRP} ; \# \mathrm{p}=0.004$ $v$ PRP.

\section{Results}

Table 2 shows the results unadjusted for age. VWF concentrations were significantly greater in patients with lcSSc and dSSc compared with controls ( $p=0.005$ and $p=0.009$, respectively) and compared with patients with PRP $(p=0.03$ and $p=0.02$, respectively) (fig 1$)$. Soluble thrombomodulin and thromboxane concentrations were not significantly different between groups. The difference between $\beta$-thromboglobulin in patients with $1 \mathrm{cSSc}$ and controls was of borderline statistical significance $(p=0 \cdot 05)$. There were no significant differences in any of the fibrinolytic parameters between patients and controls, but PAI-1 concentrations were smaller in patients with lcSSc than in patients with PRP $(p=0.004)$. There was a linear trend across the different groups for thromboxane $(p=0.009)$ and tissue plasminogen activator antigen $(\mathrm{p}=0.03)$, in addition to VWF $(\mathrm{p}<0.0001)$ (fig 1), to increase with disease severity: patients with dSSc had the greatest values.

Patients with $\mathrm{lcSSc}$ and dSSc were older than controls $(p=0.002$ and 0.007 , respectively). There were no significant differences in disease duration between groups.

After adjustment for age and smoking, VWF concentrations were significantly greater only in the subgroup with dSSc compared with controls and patients with PRP $(p=0.01)$. Linear trends across groups for thromboxane, tissue plasminogen activator antigen, and

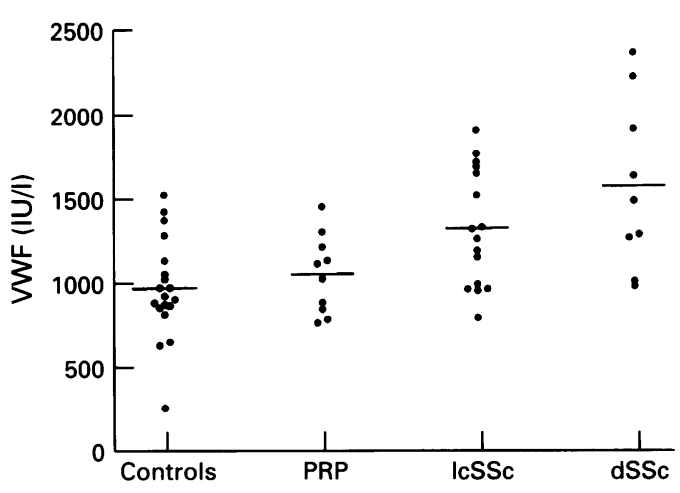

Figure 1 Plasma concentrations of von Willebrand factor (VWF) in control subjects and patients with primary Raynaud's phenomenon (PRP), limited cutaneous (lcSSc), or diffuse (dSSc) systemic sclerosis.
VWF concentrations after adjustment for age, smoking, and multiple comparisons were as follows: $p=0.06$ for thromboxane, $p=0.08$ for tissue plasminogen activator antigen, and $\mathrm{p}=0.002$ for VWF.

The following variables correlated with one another:

(1) patient's age with VWF $(r=0.38$, $\mathrm{p}=0.005)$ and with tissue plasminogen activator activity $(\mathrm{r}=0.35, \mathrm{p}=0.015)$;

(2) thromboxane with $\beta$-thromboglobulin $(r=0.60, \mathrm{p}<0.001)$;

(3) PAI-1 negatively with tissue plasminogen activator activity $(r=-0.48, p=0.001)$ and negatively with $\beta$-thromboglobulin $(r=-0.36, \mathrm{p}=0.01)$.

Discriminant analysis was performed to produce a combined index of thromboxane and VWF adjusted for age and smoking, to discriminate between controls and SSc patients. The discriminant function correctly classified 13 of $18(72 \cdot 2 \%)$ controls and 15 of $24(62.5 \%)$ SSc patients. The discriminant scores showed a trend to increase with disease severity across the four groups $(p=0.0002)$ (fig 2).

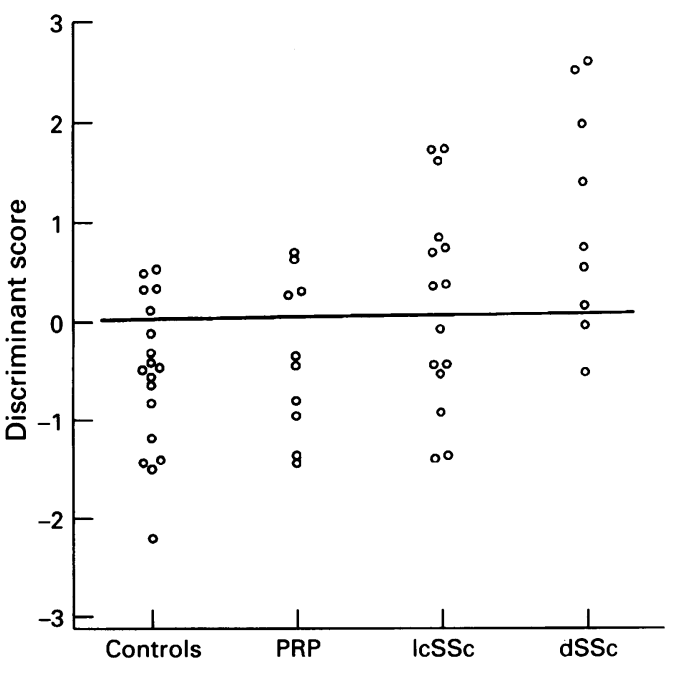

Figure 2 Discriminant scores from an analysis of von Willebrand factor and thromboxane (age and smoking adjusted) to discriminate between controls and patients with primary Raynaud's phenomenon (PRP), limited cutaneous $(I c S S c)$ and diffuse (dSSc) systemic sclerosis. Scores less than zero indicate prediction of control group. 


\section{Discussion}

Our results suggest that plasma concentrations of VWF may reflect disease severity in patients with Raynaud's phenomenon; patients with SSc, particularly those with diffuse disease, had greater concentrations than patients with PRP or healthy control subjects. There was also a trend for thromboxane and tissue plasminogen activator antigen concentrations to be greater in patients with more severe disease.

Previous workers have investigated markers of vascular damage, platelet aggregation, and fibrinolysis in patients with PRP and SSc. However, in our study the analysis of markers of all these processes was simultaneous and under carefully controlled conditions in a series of patients with Raynaud's phenomenon, subdivided into those with PRP and those with the limited cutaneous and diffuse variants of SSc. We also sought correlations between concentrations of these different markers. As expected, tissue plasminogen activator activity correlated negatively with PAI-1. $\beta$-Thromboglobulin correlated with thromboxane, probably reflecting the fact that concentrations of both increase with platelet activation. Finally, PAI-1 correlated negatively with $\beta$-thromboglobulin. The significance of this last observation is not clear. The lack of correlation between other parameters, for example, between VWF and thromboxane, reflects that they are markers of different processes.

Many workers have now shown that VWF is increased in patients with $\mathrm{SSc}^{3-12}$ The situation in PRP is more confused, some workers describing increased VWF in PRP, ${ }^{3} 6811$ while others have not. ${ }^{10} 12$ In our present study, plasma concentrations of VWF in patients with PRP were not significantly greater than those in controls, and were significantly less than those in patients with SSc. Although the ABO blood group may influence plasma VWF concentration, ${ }^{24}$ it was not measured in our study; however, we have no reason to expect that the distribution of $\mathrm{ABO}$ blood group differed significantly between the control and disease groups.

It is likely that the increased plasma concentrations of VWF are derived from endothelial cells, although VWF is also found in megakaryocytes and platelets. Kahaleh et al have shown abnormal platelet-collagen interactions in SSc; platelet activation could result in increased release of platelet granule contents. ${ }^{25}$ Increased concentrations of VWF are likely to perpetuate vascular injury, VWF having a role in platelet aggregation and adhesion to the subendothelium of an injured vessel wall. ${ }^{26}$

With the exception of that by Belch $e t$ al in $1987,{ }^{6}$ all the studies quoted above have, in common with our own, only measured VWF cross-sectionally in patients with Raynaud's phenomenon. Of interest in the study by Belch's group is that, though the number of patients studied longitudinally was small (11 studied longitudinally, of whom six had SSc or developed this during the period of observation), the concentrations of VWF did seem to correlate with disease progression. Lee et al found some correlation between VWF concentration and severity of vascular abnormalities as judged by nail fold microscopy. ${ }^{4}$

Thrombomodulin is a vascular endothelial surface glycoprotein receptor for protein C, protein $S$, and $\alpha$-thrombin. Assembly of this complex on thrombomodulin leads to activation of protein C. Vascular endothelial damage has been shown to result in the release into the circulation of cleavage fragments of thrombomodulin varying in molecular weight from 28 to $112 \mathrm{kDa}$ (soluble thrombomodulin). Increased concentrations of soluble thrombomodulin have been demonstrated in patients with vasculitis, and are thought to be a specific indicator of vascular endothelial injury. ${ }^{27} 28$ In contrast to the findings of two previous reports, we were unable to demonstrate increased concentrations of soluble thrombomodulin in patients with SSc. ${ }^{27}{ }^{28} \mathrm{We}$ suspect that VWF is a more sensitive indicator of vascular endothelial injury than soluble thrombomodulin, although less specific.

We found that plasma concentrations of thromboxane were increased (though not significantly) in patients with SSc. Reilly et al found increased urinary excretion of the thromboxane metabolite 2,3-dinor-thromboxane $B_{2}$ in patients with SSc, and proposed that biosynthesis of thromboxane $\mathbf{A}_{2}$ is enhanced in patients with SSc. ${ }^{13}$ These authors also suggested that measuring blood concentrations of thromboxane $\mathbf{B}_{2}$ was a less satisfactory method of estimating thromboxane biosynthesis because of the possibility of in vitro platelet activation. In our study, we took care to minimise platelet activation, and patients with difficult venous access were not included. The fact that thromboxane biosynthesis increased with cooling in the study by Reilly's group suggests that thromboxane may be important in the pathophysiology of vasospasm in patients with SSc.

Increased concentrations of thromboxane and $\beta$-thromboglobulin indicate platelet activation. This was seen in our SSc patients, but was of statistical significance only for $\beta$-thromboglobulin and only in the patients with $\mathrm{lcSSc}$. As anticipated, concentrations of thromboxane correlated with those of $\beta$-thromboglobulin. Several authors have reported increases in $\beta$-thromboglobulin in patients with SSc. ${ }^{41-18}$ This suggests that platelet activation occurs in SSc.

Fibrinolysis has been shown to be impaired in patients with Raynaud's phenomenon secondary to SSc and other connective tissue disorders. ${ }^{19} 20$ In our current study, tissue plasminogen activator activity did not differ significantly between groups, suggesting no major impairment of fibrinolysis. There was a trend for tissue plasminogen activator antigen to increase with disease severity. Marasin et $a l^{10}$ found that tissue plasminogen activator antigen was increased in patients with SSc, but not in those with PRP. Tissue plasminogen activator antigen is a product of endothelial cells: increased concentrations might reflect endothelial cell activation. In conditions in 
which PAI-1 is increased, the tissue plasminogen activator activity tends to be decreased, in keeping with our finding of a negative correlation between these two parameters. Our finding that parameters of fibrinolysis were similar in patients with PRP and controls is in keeping with our previous work $^{19}$ and that of Lau et al, ${ }^{20}$ who discussed previous contradictory results in relation to whether or not patients with PRP exhibit abnormal fibrinolysis. The reason for the decreased PAI-1 in patients with lcSSc compared with those with PRP is not clear.

In our study, patients with either subgroup of SSc were older than controls. Age correlated with VWF, as previously reported, ${ }^{11}$ and with tissue plasminogen activator activity. Another factor which could have affected the results was smoking habit: smokers have been shown to have greater circulating concentrations of VWF, ${ }^{29}$ increased biosynthesis of thromboxane, ${ }^{30}$ and reduced fibrinolysis ${ }^{31} 32$ compared with non-smokers. An age and smoking habit adjusted analysis was therefore performed. Linear trends with disease severity were most apparent for VWF and thromboxane, and this prompted us to perform a discriminant analysis to examine if a combined index of these two parameters, one a marker of endothelial damage/activation and the other of platelet activation, might discriminate between SSc patients and controls. While this proved not to be the case, with more than $25 \%$ of patients and controls being wrongly classified, there was nonetheless, as shown in figure 2, a powerful trend for this discriminant score to increase with disease severity across the four patient/control groups examined, suggesting that this might be a useful index to incorporate into longitudinal studies.

Patient numbers were admittedly small, but we can nevertheless conclude from our study that, in patients with Raynaud's phenomenon, increased circulating concentrations of VWF tend to be associated with disease severity, the greatest concentrations being found in that sub-group of SSc patients with diffuse disease. The study lacked the power to allow us to make firm statements about the relevance of the differences regarding platelet activation and fibrinolysis between groups, but there was a linear trend for thromboxane and tissue plasminogen activator antigen to differentiate between different subgroups of patients with Raynaud's phenomenon. In patients with PRP, these parameters were no different from those of controls. These findings lend support to previous work implicating endothelial injury and platelet activation in SSc, and to the concept that measurement of VWF concentrations, though far from ideal, ${ }^{33}$ may currently provide the most useful marker of endothelial cell integrity in this clinical context.

This was a cross-sectional study examining a range of markers of endothelial and platelet activation/damage. Prospective studies are now required, to examine patients presenting with Raynaud's phenomenon (both primary and secondary) at different times in the evolution of their disease, to examine if the con- centrations of markers of endothelial injury and of platelet aggregation increase as disease progresses. If they do, then markers of these processes could be used as objective markers of disease severity. Such objective markers are greatly needed, to help in interpretation of clinical trials in primary and secondary Raynaud's phenomenon.

1 Campbell P M, LeRoy E C. Pathogenesis of systemic sclerosis: a vascular hypothesis. Semin Arthritis Rheum $1975 ; 4: 351-68$

2 Jayson M I V. Systemic sclerosis: a collagen or microvascular disease? $B M F$ 1984; 288: 1855-7.

3 Kahaleh M B, Osborn I, LeRoy E C. Increased factor VIII/ von Willebrand factor antigen and von Willebrand factor activity in scleroderma and in Raynaud's phenomenon. Ann Int Med 1981; 94: 482-4.

4 Lee P, Norman C S, Sukenik S, Alderdice C A. The clinical significance of coagulation abnormalities in systemic significance of coagulation abnormalities in system
sclerosis (scleroderma). $₹$ Rheumatol $1985 ; 12: 514-7$.

5 Mannucci P M, Lombardi R, Lattuada A, Perticucci E Valsecchi R, Remuzzi G. Supranormal von Willebrand factor multimers in scleroderma. Blood 1987; 73: 1586-91.

6 Belch J J F, Zoma A A, Richards I M, McLaughlin K Forbes C D, Sturrock R D. Vascular damage and factorVIII-related antigen in the rheumatic diseases. Rheumato Int 1987; 7: 107-11.

7 Greaves M, Malia R G, Milford Ward A, et al. Elevated von Willebrand factor antigen in systemic sclerosis: relationship to visceral disease. $B r \mathcal{F}$ Rheumatol 1988; 27 281-5.

8 James J P, Stevens T R J, Hall N D, et al. Factor VIII related antigen in connective tissue disease patients and relatives. antigen in connective tissue disea

9 Matucci-Cerinic M, Pignone $\mathrm{P}$, Lotti $\mathrm{T}$, et al Reduced angiotensin converting enzyme plasma activity in scleroderma. A marker of endothelial injury? $\mathcal{f}$ Rheumato 1990; 17: 328-30.

10 Marasini B, Cugno M, Bassani C, Stanzani M, Bottasso B, Agostoni A. Tissue-type plasminogen activator and von Willebrand factor plasma levels as markers of endothelia involvement in patients with Raynaud's phenomenon. In f Microcirc Clin Exp 1992; 11: 375-82.

11 Blann A D, Illingworth K, Jayson M I V. Mechanisms of endothelial damage in systemic sclerosis and Raynaud's phenomenon. $₹$ Rheumatol 1993; 20: 1325-30.

12 Goodfield M J D, Orchard M A, Rowell N R. Whole blood platelet aggregation and coagulation factors in patients platelet aggregation and coagulation factors in patients

13 Reilly I A G, Roy L, Fitzgerald G A. Biosynthesis of thromboxane in patients with systemic sclerosis and Raynaud's phenomenon. BMF 1986; 292: 1037-9.

14 Kahaleh M B, Osborn R, LeRoy E C. Elevated levels of circulating platelet aggregates and beta-thromboglobuli in scleroderma. Ann Int Med 1982; 96: 610-3.

15 Kallenberg C G M, Vellenga E, Wouda A A, The T $H$ Platelet activation, fibrinolytic activity and circulating immune complexes in Raynaud's phenomenon. f Rheumatol 1982; 9: 878-84.

16 Hutton R A, Mikhailidis D P, Bernstein R M, Jeremy J Y, Hughes G R V, Dandona P. Assessment of platelet function in patients with Raynaud's syndrome. $\mathcal{F}$ Clin Pathol 1984; 37: 182-7.

17 Siebold J R, Harris J N. Plasma $\beta$-thromboglobulin in the differential diagnosis of Raynaud's phenomenon 7 Rheumatol 1985; 12: 99-103.

18 Lima J, Fonollosa V, Fernandez-Cortijo J, et al. Platelet activation, endothelial cell dysfunction in the absence of anticardiolipin antibodies in systemic sclerosis. f Rheumatol 1991; 18: 1833-6.

19 Holland C D, Jayson M I V. Venous blood fibrinolysis and fibrinolytic potential in primary Raynaud's phenomenon and systemic sclerosis associated with Raynaud's phenomenon. In: Black C M, Myers A R, eds. Progressive systemic sclerosis. New York: Gower, 1985; 267-73.

20 Lau C S, McLaren M, Mackay I, Belch J J F. Baseline plasma fibrinolysis and its correlation with clinical manifestations in patients with Raynaud's phenomenon. Ann Rheum Dis 1993; 52: 443-8.

21 Bachmann F, Kruithof I E K O. Tissue plasminogen activator: chemical and physiological aspects. Semin Thromb Hemost 1984; 10: 6-17.

22 Subcommittee for Scleroderma Criteria of the American Rheumatism Association Diagnostic and Therapeutic Criteria Committee. Preliminary criteria for the classification of systemic sclerosis (scleroderma). Arthritis Rheum 1980; 23: 581-90.

23 Blann A D, Hopkins J, Winkles J, Wainwright A C. Plasm and serum von Willebrand factor antigen concentration in connective tissue disorders. Ann Clin Biochem 1992; 29: 67-71.

24 Gill J C, Endres-Brooks J, Bauer $P$ J, Marks W J Montgomery R R. The effect of ABO blood group on the diagnosis of von Willebrand disease. Blood 1987; 69, 1691-5.

25 Kahaleh M B, Scharstein K K, LeRoy E C. Enhanced platelet adhesion to collagen in scleroderma. Effect 

of scleroderma plasma and scleroderma platelets.

26 Blann A D. Von Willebrand factor as a marker of injury to the endothelium in inflammatory vascular disease. f Rheumatol 1993; 20: 1469-71.

27 Soma Y, Takehara K, Sato S, Ishibashi Y. Increase in plasma thrombomodulin in patients with systemic sclerosis. F Rheumatol 1993; 20: 1444-5.

28 Ohdama S, Takano S, Miyake S, Kubota T, Sato K, Aoki N. Plasma thrombomodulin as a marker of vascular injuries in collagen vascular diseases. Am $\mathcal{f}$ Clin Pathol 1994; 101: 109-13.

29 Blann A D, McCollum C N. Adverse influence of cigarette smoking on the endothelium. Thromb Haemost 1993; 70 707-11.
30 Dotevall A, Rangemark C, Eriksson E, Kutti J, Wadenvik $H$, Wennmalm A. Cigarette smoking increases thromboxane A2 formation without affecting platelet survival in young healthy females. Thromb Haemost 1992; 68: 583-8.

31 Belch J J F, McArdle B M, Burns P, Lowe G D O Forbes $C D$. The effects of acute smoking on platelet behaviour, fibrinolysis and haemorheology in habitual smokers. Thromb Haemost 1984; 51: 6-8.

32 Haire W D, Goldsmith J C, Rasmussen J. Abnormal fibrinolysis in healthy male cigarette smokers: role of flasminogen activator inhibitors. Am $\mathcal{f}$ Hematol 1989; 31: plasmin.

33 Blann A D, Taberner D A. A reliable marker of endothelial cell dysfunction: does it exist? Br f Haematol. In press. 